\title{
Workplace Support Systems in Small- and Medium-Sized Companies for Employees Receiving Medical Treatment in Japan
}

\author{
Ryoko Rikitake ${ }^{1,2}$, Satoru Kamitani ${ }^{1}$, Miyako Takahashi ${ }^{3} \&$ Takahiro Higashi $^{1}$ \\ ${ }^{1}$ Division of Health Services Research, Center for Cancer Control and Information Services, National Cancer \\ Center, Tokyo, Japan \\ ${ }^{2}$ Department of Otolaryngology and Head and Neck Surgery, Graduate School of Medicine, the University of \\ Tokyo, Tokyo, Japan \\ ${ }^{3}$ Division of Cancer Survivorship Research, Center for Cancer Control and Information Services, National \\ Cancer Center, Tokyo, Japan \\ Corresponding: Takahiro Higashi, MD, PhD, Division of Health Services Research, Center for Cancer Control \\ and Information Services, National Cancer Center, Tokyo, Japan, 5-1-1 Tsukiji, Chuo-ku, Tokyo 1040045, Japan. \\ Tel: 81-3-3547-5201; Fax: 81-3-5565-2322. E-mail: thigashi@ncc.go.jp
}

Received: January 6, 2020 Accepted: February 12, 2020 Online Published: February 15, 2020

doi:10.5539/gjhs.v12n3p91 URL: https://doi.org/10.5539/gjhs.v12n3p91

\begin{abstract}
Background: Maintaining one's current job is important for patients. Few studies have investigated the presence of support systems in small- and medium-sized companies to help balance the therapeutic needs and occupational roles of workers in Japan.
\end{abstract}

Aims: To understand whether small- and medium-sized companies in Japan have established workplace policies to help employees with chronic disease balance medical treatment and professional life.

Methods: We surveyed a sample of small- and medium-sized companies in Japan identified from a large database of corporate credit and marketing research companies between February and March 2017. A questionnaire addressed workplace policies that supported employees' medical treatments and professional lives, such as flexible work arrangements and the preparation of manuals and forms to facilitate communication with treating physicians.

Results: Of the 4158 companies initially contacted, 1140 companies (27\%) responded to the survey. Of the valid respondents, $21 \%$ of the workplaces reported having established sufficient office rules to address employee's necessary medical needs. Approximately half of the workplaces $(53 \%)$ shared that they had a system in place to provide temporary medical leave for employees with chronic diseases. Few (12\%) workplaces had established a process for having a trial return to work after a period of absence due to a medical condition.

Conclusions: Currently, a minority of small- and medium-sized companies in Japan have established workplace policies to address the medical needs of employees with chronic diseases.

Keywords: chronic disease, database, Japan, questionnaire, work-life balance, workplace

\section{Introduction}

Maintaining a job is important for workers with chronic diseases, as it not only helps them to pay their medical bills but also enables them to maintain a connection with their community (Soja, 2019). The recent ageing of society has contributed to a rise in the average age of workers, and the number of workers with chronic diseases is increasing. As the prevalence of chronic diseases goes up, society must pay greater attention to how they can develop systems to support patients, which enable them to pursue the best medical treatment while maintaining their employment.

Chronic diseases generally require medical care for an extended period, (Ervasti, 2015; Reeuwijk, 2014; Tamminga, 2010) especially for serious diseases, such as cancer. Many patients with cancer require temporary leave from work during their initial course of treatment. Even after this treatment, patients may need to go to clinics for ongoing treatment and follow-up appointments to check for recurrences. Due to the dramatic improvements in the survival rates of cancer patients (i.e., about half of all cancer patients live longer than 10 years), (Cancer Statistics, 2018) more cancer survivors must balance their treatment needs and occupational goals 
(Hori, 2015). Therefore, support for cancer survivors has become essential. Temporary leave and return to work have become common (Endo, 2016; Kiasuwa, 2016; Paalman, 2016; Leijten, 2015). Thus, to encourage the employee's successful return to work and retention, workplaces must develop support systems for workers' readjustment (Eguchi, 2017; White, 2013; Sampere, 2011; Mehnert, 2011; Tanaka, 2011).

Employers also benefit from keeping skilled workers in the workforce for as long as their health permits them to work. Support for workers with chronic medical conditions is vital for small- and medium-sized companies, who usually have insufficient substitutes for skilled workers. However, they often lag behind larger companies in preparing for their employee's sick leave. Previous studies conducted in Tokyo have shown that among large companies with over 300 employees, $91 \%$ have established procedures to enable the employees to keep their job while receiving medical care, or to provide insurance or economic support for employees with medical conditions; $85 \%$ have established systems to accept consultation by occupational health staff about their employees' health conditions, while only $70 \%$ and $36 \%$ of small- and medium-sized companies have these support services in place, respectively (Bureau of Social Welfare, 2014; Japan Institute, 2005). Thus, there is a sizable gap in support levels between large- and small-/medium-sized companies. Moreover, a study conducted in Chiba prefecture in Japan showed a similar gap with $95 \%$ of large-scale companies having established office rules for support compared to $71 \%$ of small- and medium-sized companies (Sakamoto, 2017).

The situation in small-/medium-sized companies is concerning, as Japanese society comprises many small- and medium-sized companies, accounting for over $99 \%$ of all companies and employing $70.1 \%$ of the workforce (Summary of White Book, 2016). However, little is known about support systems that exist in these companies. Although a previous study surveyed companies located in 6 prefectures in Japan (Bureau of Social Welfare, 2014; Japan Institute, 2005; Sakamoto, 2017; Hiroshima Prefecture, 2014; Shimane Prefecture, 2017; Shiga Prefecture, 2015; Aichi Prefecture, 2014), a nationwide study to investigate the support systems in small- and medium-sized companies to help workers balance their medical needs and occupational lives has not been conducted. The importance of this problem has led to the publication of the Guideline for Supporting Work-Treatment Balance in the Workplace by the Ministry of Health, Labour and Welfare in Japan in 2016 (Guideline, 2016), but to date, research has not examined the current implementation status of these guidelines. This study aimed to examine if small- and medium-sized companies in Japan have developed support systems to help workers with chronic diseases balance their medical treatments and occupational lives.

\section{Methods}

We conducted a cross-sectional survey of small- and medium-sized companies in Japan between February and March 2017. We sampled companies using a database maintained by a credit and marketing research company (Teikoku Databank, https://www.tdb.co.jp/english/index.html). This database includes information on companies operating in Japan. These data were collected during corporate credit research. The survey was created based on the Japanese guideline (Ministry of Health, Labour and Welfare, 2016) issued by the Ministry of Health, and the survey wording was carefully chosen and checked by multiple researchers. We believe that the questions captured what they asked.

\subsection{Participants}

The companies in this study were classified according to the Small and Medium Enterprise Agency of the Japanese Ministry of Economy, Trade and Industry (Small and Medium, 2014). According to this definition, the number of employees who work in small- and medium-sized companies vary between business categories. For businesses involving agriculture, forestry, fishery, mining, construction, manufacturing, transportation, and telecommunication, companies with 300 employees or fewer are small- or medium-sized. For businesses involving wholesale, retailing, restaurant, finance, insurance, real estate, electricity, gas, water, utility, heat supply, and service, businesses with 100 employees or fewer are small- or medium-sized. Companies with fewer than 10 employees, public companies, and companies not in classifiable categories were excluded from this study.

We stratified the sampling of companies based on the industrial category and the number of employees. First, we divided the numbers of employees into 7 strata: 10-20, 21-30, 31-40, 41-50, 51-100, 101-200, and 201-300. Next, we randomly sampled 70 companies from each stratum. If the number of companies included in each stratum was fewer than 70, all the companies in the stratum were sampled.

\subsection{Sampling Procedure}

We developed a questionnaire based on the workplace support systems proposed in the Guideline for Supporting Work-Treatment Balance in the Workplace (2016) published by the Ministry of Health, Labour and Welfare in Japan (Guideline, 2016). The guideline targets all workers, including workers who need continuous treatment for chronic diseases such as cancer, stroke, cardiovascular diseases, diabetes mellitus, and hepatitis. It proposes approaches for establishing a supportive workplace environment, responding to an employee's necessary 
therapeutic needs, and supporting workers' ability to receive appropriate treatment while maintaining employment. It includes sample forms to help companies communicate with employees' primary physicians regarding employees' capacity to work and restrictions required at work.

Our questionnaire consisted of 17 Yes-or-No questions grouped into 4 major parts (Table 1): A) workplace policies and rules to support employees to balance treatments and occupational lives, B) adoption of flexible arrangement for workers, C) availability of specific forms to communicate with treating doctors, and D) employers' knowledge about the subsidy and/or support available outside the company.

We asked the respondents to answer thinking of employees who would need repeated and continuous treatment for an extended period. The survey instructed respondents to focus on physical diseases. While non-physical (psychiatric) conditions sometimes have courses of treatment, they may be different from physical diseases.

We mailed the questionnaire to 4158 companies between February and March 2017. Companies who failed to respond were reminded once by telephone in March 2017. We addressed the questionnaire to top management of each company and asked that the survey be delivered to the appropriate department.

\subsection{Analysis}

Results were analyzed using descriptive statistics to identify the current status of policies in small- and medium-sized companies to support their employees' work-treatment balance. We further analyzed the differences across the 10 geographical regions in Japan: Hokkaido (northern island), Tohoku (northern part of main island), Northern Kanto and Koshin (north of Tokyo area), Southern Kanto (Tokyo and surrounding area), Hokuriku (northwest part of main island), Tokai (Nagoya area), Kinki (Kyoto and Osaka areas), Chugoku (western part of main island), Shikoku (Southwestern island), and Kyushu (Western island) and Okinawa (see Appendices A). Since the companies were sampled with equal numbers after stratification by size and type of industry, and the response rates varied across strata, their responses were assigned weights according to the number of companies that responses were expected to represent so that our results would reflect the total population.

Along with calculating the proportions of respondent companies with each work support system, we summarized the level of support system implementation in each company by counting the number of support systems that the company had (i.e., "yes" responses to each question about the company's existing systems and rules). The differences in the proportions of companies with each support system/rule and the number of support system/rules each company had were tested using chi-square and Kruskal-Wallis tests, respectively. Statistical significance was set at $p<.05$. All analyses were performed using Stata version 13 (StataCorp LP, College Station, TX, USA).

This study was approved by the Institutional Review Board of the National Cancer Center, Japan.

\section{Results}

Of the 4158 companies that were initially contacted, 1140 companies $(27 \%)$ responded to the survey. Demographic characteristics of the small- and medium-sized companies $(n=1140)$ that completed the survey are shown in Table 2. Companies with fewer than 100 employees in the workplace accounted for $90 \%(n=1025)$ of the respondents. Responses came from the various categories of businesses around the country. There was no deflection in the industrial categories and geographic areas.

The presence of systems/rules/knowledge in the company and their differences across geographic regions are listed in Table 3. Appropriate office rules to accommodate employee's medical needs were established in $21 \%$ of the workplaces, and $81 \%$ of them reported that the rules were made well-known to all the employees. In contrast, few companies $(2 \%)$ provided training to managers on how to handle employees' health problems in the workplace. Likewise, few companies (2\%) provided education to all employees on how to help other employees balance their medical treatments and professional lives. Half of the workplaces (52\%) stated that they had affiliated or in-house health staff who could consult with employees who had medical needs; however, only $4 \%$ had clearly shared information about these programs with their employees. More than half the employees (56$89 \%$ ) in the workplaces who had affiliated/in-house health staff had actually consulted with the available staff.

Results on the flexible work arrangement items varied. While more than half of the workplaces (62\%) had systems for half-day paid-leave, only $22 \%$ had an hourly-based paid-leave option. About half of the workplaces (53\%) had established a system of medical leave. However, the proportions of workplaces which had a policy to allow flexible work hours or temporary shortened work hours were $19 \%$ and $28 \%$, respectively. Few workplaces (12\%) had established a system of a trial return to work for employees with chronic medical conditions.

Workplaces that had special forms to communicate with the treating doctors of the employees with health problems about their treatment, capacity, and capability to work were scarce (3-4\%). Employers' knowledge about subsidies that could help in retaining workers and their return to work was also scarce $(6 \%)$. Their 
knowledge about occupational health support centers was also poor (13\%) and only $5 \%$ of workplaces actually used the center. On average, 3.2 out of the 17 potential recommendations in the guideline that supported work-treatment balance were implemented by the surveyed companies, as represented by the "Yes" responses.

With few exceptions, there were no statistically significant geographical area differences in the level of workplace support services. The proportion of employers who established systems of half-day paid-leave was higher (86\%) in Northern Kanto and Koshin, but only 36\% and $48 \%$ in Hokkaido and Tohoku ( $p<.01$, Kruskal-Wallis test). Telecommuting was implemented in 3-4\% of the companies in Northern and Southern Kanto Hokuriku, and Kinki, while it was implemented in approximately $1 \%$ of companies in other areas in Japan.

Figure 1 shows the histogram of the number of companies in relation to the number of "Yes" responses to the survey. The histogram was skewed left with the median number of "Yes" responses being 3 .

Table 1. List of questions on the questionnaire

\begin{tabular}{|c|c|}
\hline Question Items & Item Descriptors \\
\hline \multicolumn{2}{|l|}{ A. Workplace policies and rules to support employees' treatment needs } \\
\hline 1. "Are there office rules to accommodate employee's medical needs?" & 1. Office rules/systems for support \\
\hline \multicolumn{2}{|l|}{ 1-1. "Are the rules made visible to all employees?" } \\
\hline $\begin{array}{l}\text { 2. "Does the company give managerial staff any education on how to manage } \\
\text { employees with health problems?" }\end{array}$ & 2. Education for the managerial staff \\
\hline 2-1. "Does the education include the following: & 2-1. Education includes: \\
\hline Materials to promote understanding of how to manage workers with health problems & Materials for understanding \\
\hline $\begin{array}{l}\text { Information on existing support systems and company rules to enable the workers to } \\
\text { balance the treatment needs and work }\end{array}$ & Info about support policy/rules \\
\hline $\begin{array}{l}\text { Education on available resources outside the company to support the workers with } \\
\text { chronic problems }\end{array}$ & Info about outside resources \\
\hline Other" & Other \\
\hline $\begin{array}{l}\text { 3. "Does the workplace provide education to all employees on ways to help other } \\
\text { employees balance their medical treatments and professional lives?" }\end{array}$ & 3. Education for all employees \\
\hline 3-1. "Does the education include the following: & 3-1. Contents of education \\
\hline Materials to promote understanding of how to manage workers with health problems & Materials for understanding \\
\hline $\begin{array}{l}\text { Information on existing support systems and company rules to enable the workers to } \\
\text { balance the treatment needs and work }\end{array}$ & Info about support policy/rules \\
\hline $\begin{array}{l}\text { Education about the outside system and guidelines to support the workers with } \\
\text { chronic problems }\end{array}$ & Info about outside resources \\
\hline Other" & Other \\
\hline $\begin{array}{l}\text { 4. "Does the workplace have established and confidential consultants who can } \\
\text { address employee's medical needs?" }\end{array}$ & 4. Consultation system \\
\hline \multicolumn{2}{|l|}{ B. Adoption of flexible work arrangements } \\
\hline $\begin{array}{l}\text { 5. "Does the company grant a half day of paid leave to employees seeking medical } \\
\text { treatment?" }\end{array}$ & 5. Paid-leave by the half-day \\
\hline 6. "Does the employer grant hourly-based paid medical leave to employees?" & 6. Paid-leave by the hour \\
\hline 7. "Does the company grant extended medical leave to employees?" & 7. Sick-day leave \\
\hline 8. "Does the workplace have a policy to allow staggered work hours?" & 8. Flexible work hours \\
\hline 9. "Does the workplace have a policy to allow shortened office hours?" & 9. Temporary shortened work hours \\
\hline 10. "Does the workplace have a policy to allow telecommuting?" & 10. Telecommuting \\
\hline 11. "Does the workplace have a policy to allow a trial return to work?" & 11. A trial return to work \\
\hline \multicolumn{2}{|l|}{ C. Availability of specific forms to communicate with treating doctors } \\
\hline $\begin{array}{l}\text { 12. "Does the workplace have a specific form to communicate employees' relevant } \\
\text { work information with the treating doctor?" }\end{array}$ & $\begin{array}{l}\text { 12. Forms to notify doctors about } \\
\text { working arrangement }\end{array}$ \\
\hline
\end{tabular}


13. "Does the workplace have a specific form for treating physicians to fill in to communicate information about the details of employees' treatment and capacity to work?"

14. "Does the workplace have a specific form for the treating doctor to fill in to communicate their opinion on whether the employee is capable to return to work?"

D. Employer's knowledge about subsidy and/or support available outside the company

15. "Do you (the employer) know of 'Subsidies that your company can receive to establish the support systems/rules to allow your employees to stay in their current work?"

16. "Do you (the employer) know of "Subsidies that your company can receive to establish the support systems/rules for your employees' return to work?"

17. "Do you (the employer) know of 'The presence of occupational health support center, which receives consultations to support work-treatment balance?"”

17-1. "Have you (the employer) used the occupational health support center?" 17-1. Using support center

17-2. "Do you (the employer) know of The Guidelines for Supporting

Work-Treatment Balance in the Workplace published by the Ministry of Health,

Labour and Welfare?"

17-3. "Do you (the employer) use The Guidelines for Supporting Work-Treatment

Balance in the Workplace?

Table 2. Characteristics of the 1140 companies in the final sample

\begin{tabular}{|c|c|c|}
\hline & $n$ & $\%$ \\
\hline \multicolumn{3}{|l|}{ Industrial category } \\
\hline Agriculture & 107 & 9 \\
\hline Forestry & 54 & 5 \\
\hline Fishery & 67 & 6 \\
\hline Mining & 89 & 8 \\
\hline Construction Industry & 143 & 13 \\
\hline Manufacturing & 129 & 11 \\
\hline Wholesale, Retailing or Restaurant & 88 & 8 \\
\hline Finance or Insurance & 79 & 7 \\
\hline Real estate & 75 & 7 \\
\hline Transportation and Telecommunication & 115 & 10 \\
\hline Electricity, Gas, Water or Heat supply & 93 & 8 \\
\hline Service Industry & 101 & 9 \\
\hline Total & 1140 & 100 \\
\hline \multicolumn{3}{|l|}{ Number of employees in the workplace } \\
\hline 10-20 people & 222 & 20 \\
\hline 21-30 people & 222 & 20 \\
\hline $31-40$ people & 210 & 18 \\
\hline $41-50$ people & 174 & 15 \\
\hline $51-100$ people & 197 & 17 \\
\hline $101-200$ people & 76 & 7 \\
\hline 201-300 people & 39 & 3 \\
\hline Total & 1140 & 100 \\
\hline
\end{tabular}

13. Forms to consult doctors about the treatment status

14. Forms to ask doctor's opinion about return to work

15. Knowledge of subsides for retaining workers

16. Knowledge of subsides for return to work

17. Knowledge of support center

17-2. Knowledge of guideline

17-3. Using guideline 


\begin{tabular}{lll}
\hline Geographical Area & & 6 \\
\hline Hokkaido (Northern island) & 71 & 14 \\
Main Island & 154 & 7 \\
$\quad$ Tohoku (northern part in main island) & 75 & 20 \\
$\quad$ Northern Kanto and Koshin (north of the Tokyo area) & 228 & 7 \\
Southern Kanto (Tokyo and the surrounding area) & 81 & 11 \\
Hokuriku (north west) & 125 & 11 \\
Tokai (Nagoya area) & 128 & 7 \\
Kinki (West/Kyoto and Osaka area) & 77 & 5 \\
Chugoku (Western part) & 53 & 13 \\
Shikoku (Southwestern island) & 148 & 100 \\
Kyushu (Western island) and Okinawa & 1140 & 6 \\
\hline Total & 53 & \\
\hline
\end{tabular}

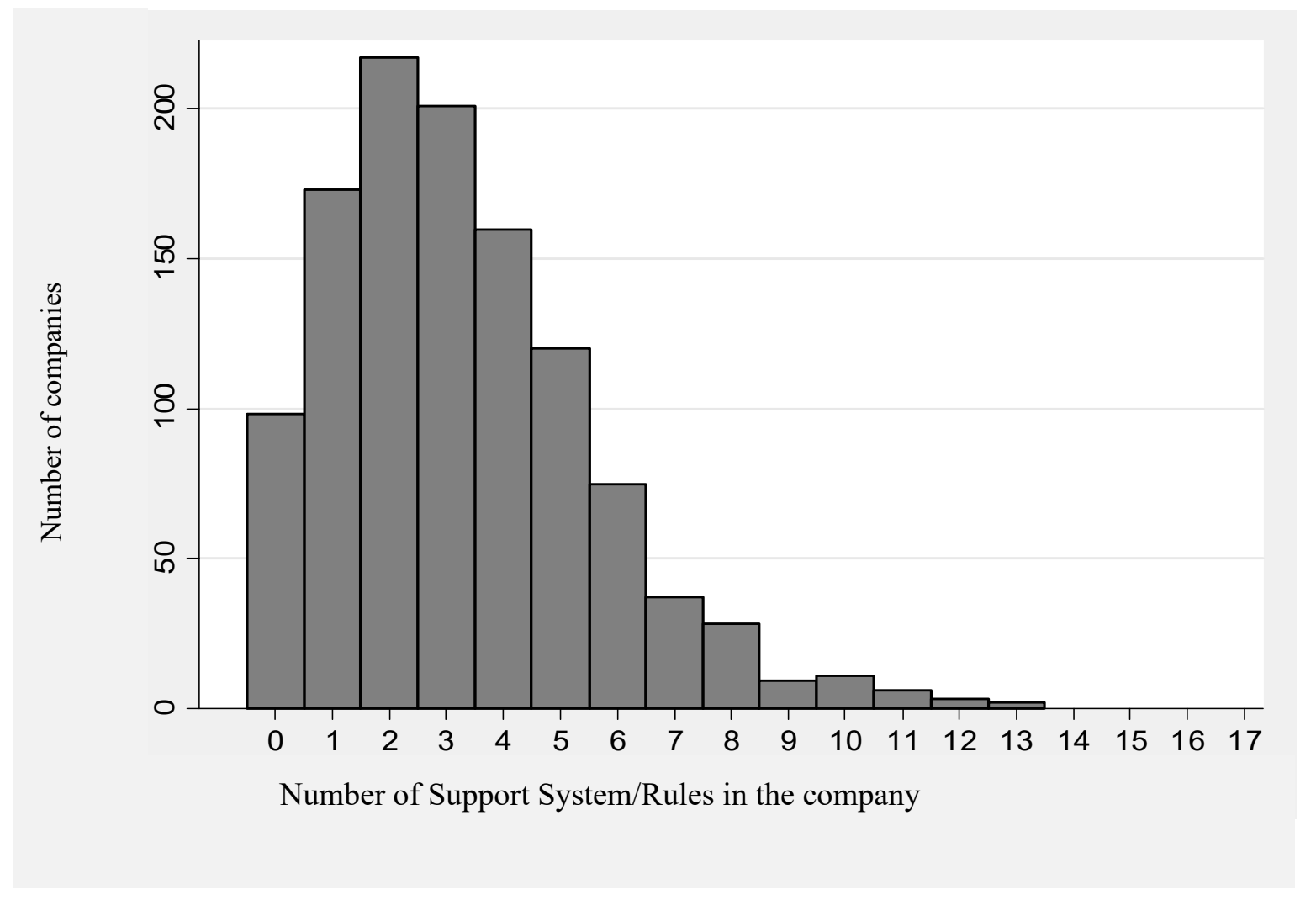

Figure 1. The distribution of companies with respect to the number of "Yes" responses to the 17 survey items Note. The number of "Yes" responses reflect the level of support policy/rules that the company has for their employees. 
Table 3. Response to each item by geography region( $\mathrm{N}=1140)$

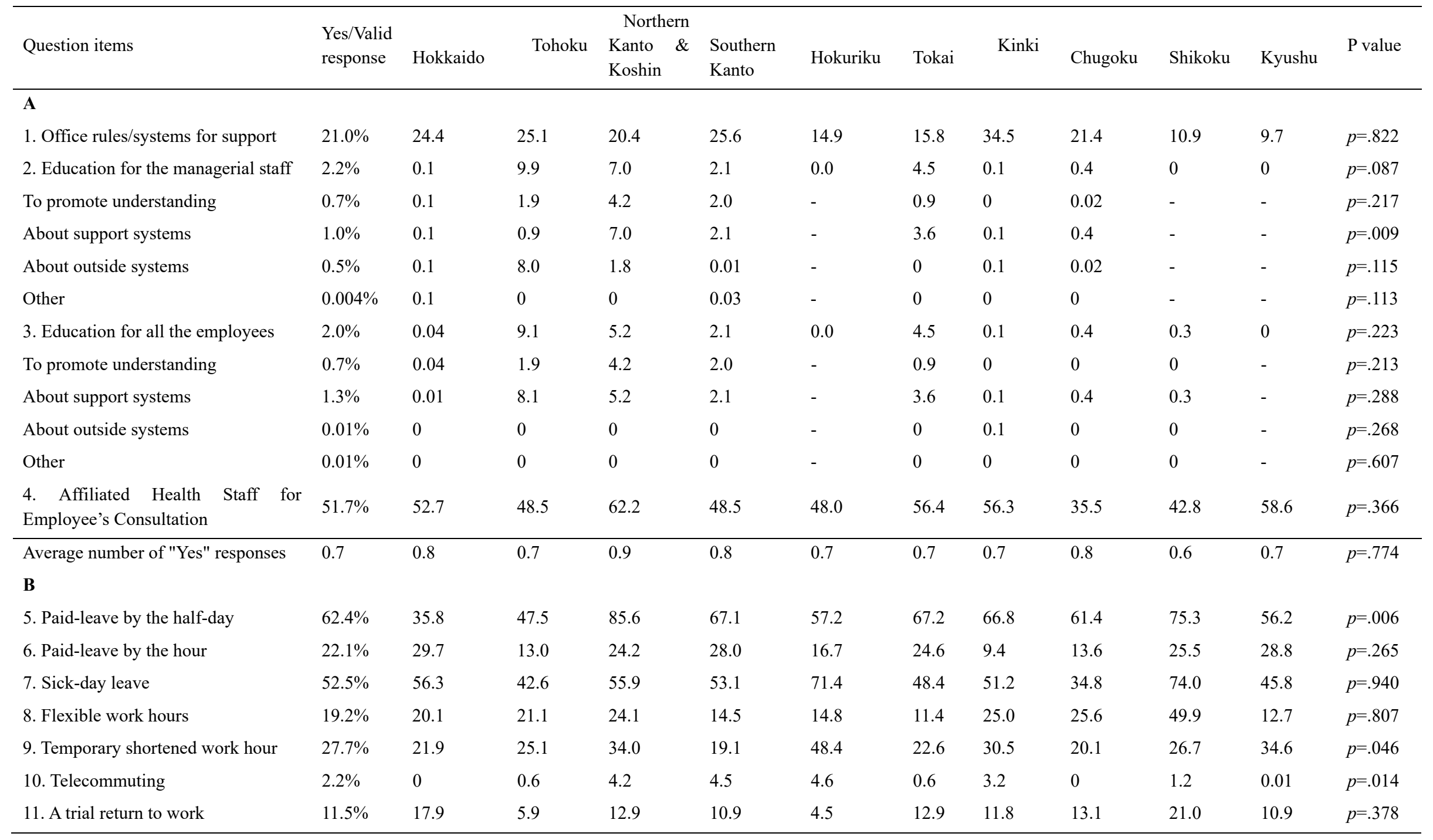




\begin{tabular}{|c|c|c|c|c|c|c|c|c|c|c|c|c|}
\hline Average number of "Yes" responses & 2.0 & 1.7 & 1.8 & 2.1 & 2.1 & 2.1 & 1.8 & 1.9 & 1.9 & 1.8 & 2.0 & $p=.252$ \\
\hline \multicolumn{13}{|l|}{$\mathbf{C}$} \\
\hline $\begin{array}{l}\text { 12. Forms to notify doctors about } \\
\text { working arrangement }\end{array}$ & $3.5 \%$ & 0.04 & 1.9 & 2.4 & 8.9 & 2.8 & 0.7 & 1.1 & 6.3 & 2.1 & 1.6 & $p=.453$ \\
\hline $\begin{array}{l}\text { 13. Forms to consult doctors about the } \\
\text { treatment status }\end{array}$ & $3.0 \%$ & 0.2 & 2.7 & 2.5 & 6.4 & 1.0 & 0.8 & 4.2 & 4.2 & 0.0 & 1.6 & $p=.853$ \\
\hline $\begin{array}{l}\text { 14. Forms to ask doctor's opinion } \\
\text { about return to work }\end{array}$ & $2.8 \%$ & 0.2 & 1.7 & 2.4 & 6.1 & 0.1 & 0.8 & 3.8 & 4.2 & 0.0 & 2.2 & $p=.376$ \\
\hline Average number of "Yes" responses & 0.1 & 0.1 & 0.1 & 0.1 & 0.2 & 0.1 & 0.1 & 0.2 & 0.2 & 0.4 & 0.1 & $p=.953$ \\
\hline \multicolumn{13}{|l|}{ D } \\
\hline $\begin{array}{l}\text { 15. Knowledge of subsides for } \\
\text { retaining workers }\end{array}$ & $5.7 \%$ & 0.5 & 3.6 & 13.1 & 4.7 & 16.7 & 5.9 & 5.2 & 7.7 & 2.6 & 1.5 & $p=.406$ \\
\hline $\begin{array}{l}\text { 16. Knowledge of subsides for return } \\
\text { to work }\end{array}$ & $6.2 \%$ & 2.1 & 5.5 & 8.4 & 6.4 & 6.2 & 6.6 & 8.9 & 7.3 & 2.9 & 5.0 & $p=.639$ \\
\hline 17. Knowledge of support center & $12.9 \%$ & 4.4 & 15.5 & 16.3 & 10.6 & 14.8 & 12.6 & 9.8 & 12.0 & 23.1 & 16.4 & $p=.046$ \\
\hline 17-1. Using support center & $4.6 \%$ & 1.5 & 12.9 & 3.5 & 1.5 & 5.0 & 8.8 & 2.7 & 3.4 & 0.3 & 6.9 & $p=.012$ \\
\hline 17-2. Knowledge of guideline & $1.3 \%$ & 1.1 & 1.8 & 1.5 & 0.3 & 0.5 & 5.8 & 0 & 0.6 & 0.2 & 0.6 & $p=.005$ \\
\hline 17-3. Using guideline & $0.003 \%$ & 0 & 0 & 0 & 0 & 0.01 & 0 & - & 0.01 & 0 & 0.01 & $p=.061$ \\
\hline Average number of "Yes" responses & 0.4 & 0.5 & 0.4 & 0.4 & 0.3 & 0.5 & 0.3 & 0.3 & 0.5 & 0.6 & 0.4 & $p=.512$ \\
\hline $\begin{array}{l}\text { Average number of "Yes" responses } \\
\text { in total }\end{array}$ & 3.2 & 3.2 & 3.1 & 3.6 & 3.4 & 3.4 & 3.0 & 3.1 & 3.4 & 3.0 & 3.3 & $p=.469$ \\
\hline
\end{tabular}

Note. All \% are weighted to make the percentages represent the whole source population.

Statistical significance was set at $\mathrm{P}<.050$. 


\section{Discussion}

This study investigated the current use of office rules and service implementation to accommodate the treatment needs of employees with chronic diseases in small- and medium-sized companies in Japan, and our results revealed that the implementation of support systems was suboptimal. While over $50 \%$ of the companies had affiliated/in-house health staff and a system for paid-leave by the unit of half-day and sick-day leave, education about the existing support system for all employees and managerial staff and the adoption of specific forms for communication with treating physicians were rare $(2-4 \%)$. Based on responses, most small- and medium-sized companies appear to lack flexibility in work styles and are not prepared to support workers with chronic diseases by communication with their employees' doctors. The lack of preparedness can lead to important employees quitting when they become ill, damaging the company's operational functions. Even if the employer cares about the sick employee, without explicit policies implemented upfront, the use of special after-the-fact arrangements to arrange for medical leave can give other workers a sense of unfairness, putting the sick employee in a difficult position. To create a supportive work environment and to achieve the best performance from all employees, smalland medium-sized companies need to establish policies and support systems that help workers with chronic diseases balance their treatment and professional lives.

Chronic health problems increase the risk of losing employment (Paalman, 2016; Leijten, 2015). Previous studies have shown that large companies tend to have better management systems for workers with mental illness, which allows them to continue working more easily than workers in small- and medium-sized companies (Doki, 2016). It is important to focus on small- and medium-sized companies, as less is known about their management systems.

Although support systems do not distinguish the type of diseases, cancer patients are especially at risk of being fired, as the side effects experienced during treatment may affect both physical and mental health (Eguchi, 2017). This risk has been acknowledged by the governmental Cancer-Control Committee, which promotes the best systematic arrangement in workplaces to achieve the best work-treatment balance, which was discussed in its 2016 publication, the Guideline for Supporting Work-Treatment Balance in the Workplace (Guideline, 2016). The guideline proposed several systems for the workplace to help establish appropriate office policies that can accommodate employee's medical needs and work-treatment balance. One study reported that breast cancer survivors tend to consult supervisors at work rather than healthcare personnel (Saito, 2014). The social support and experience of working with a colleague with another medical illness positively affected work retention in employees with chronic health problems (Eguchi, 2017; White, 2013; Sampere, 2011). In the age of living longer with chronic health problems, companies should reinforce their support systems for balancing health care needs and occupational lives.

Our study had several limitations. First, the survey was conducted only with the companies registered in the research database of Teikoku Databank. Although it is an extensive database, it only covers $45 \%$ of all companies in Japan. Additionally, the response rate was not very high. Nonetheless, the number of the rate was similar to those of other survey in the literature (Jack, 2008), and we did our best to assign weights to adjust for the non-response. However, the selection bias that companies who have established better support and are confident of their system might be more likely to respond to our survey. Furthermore, the self-report of small companies may be affected by social desirability bias, making the reported support systems appear better than reality. Nevertheless, we revealed much room for improvement in policies and services to support sick workers in small- and medium-sized companies in Japan. Third, the number of support systems/rules is a simple count of various rules and systems. Although this may over-simplify the various systems and rules, it successfully indicates the scarcity of support system/rules in these companies.

In conclusion, few small- and medium-sized companies in Japan have appropriate support systems for their employees with chronic medical illnesses. It is necessary to encourage these companies to build support systems that follow existing guidelines. Further research that focuses on barriers to establishing support systems is needed. In the future, we should identify the factors that promote and inhibit the development of appropriate office rules and economic support for employees with medical needs in small- and medium-sized companies.

\section{Acknowledgements}

The authors wish to thank the staff of all the companies that participated in this survey.

\section{Competing Interests Statement}

The authors declare that there are no competing or potential conflicts of interest. 


\section{References}

Aichi Prefecture, Japan. (2019). Questionnaire Survey About Status of Balance Support Treatment and Employment for Cancer Patients [Internet]. c2014. Japanese. Retrieved March 1, 2019, from http://www.pref.aichi.jp/uploaded/attachment/43018.pdf

Bureau of Social Welfare and Public Health, Tokyo Metropolitan Government. (2019). The Report About Status Survey on Working of Cancer Patients [Internet]. c2014. Retrieved March 1, 2019, from http://www.fukushihoken.metro.tokyo.jp/iryo/iryo_hoken/gan_portal/soudan/ryouritsu/other/houkoku.files/ honpen.pdf

Doki, S., Sasahara, S., Oi, Y., \& Matsuzaki, I. (2016). A survey of support systems for return to work in Japanese companies: a cross-sectional study. Ind Health, 54(6), 564-572. https://doi.org/10.2486/indhealth.2015-0185

Eguchi, H., Wada, K., Higuchi, Y., \& Smith, D. R. (2017). Co-worker perceptions of return-to-work opportunities for Japanese cancer survivors. Psycho-Oncology, 26(3), 309-315. https://doi.org/10.1002/pon.4130

Eguchi, H., Wada, K., Prieto-Merino, D., \& Smith, D. R. (2017). Lung, gastric and colorectal cancer mortality by occupation and industry among working-aged men in Japan. Sci Rep, 7(1), 43204. https://doi.org/10.1038/srep43204

Endo, M., Haruyama, Y., Takahashi, M., Nishiura, C., Kojimahara, N., \& Yamaguchi, N. (2016). Returning to work after sick leave due to cancer: a 365-day cohort study of Japanese cancer survivors. Journal of Cancer Survivorship, 10(2), 320-329. https://doi.org/10.1007/s11764-015-0478-3

Ervasti, J., Virtanen, M., Pentti, J., Lallukka, T., Tinghög, P., Kjeldgard, L., ... \& Alexanderson, K. (2015). Work disability before and after diabetes diagnosis: a nationwide population-based register study in Sweden. American journal of public health, 105(6), e22-e29. https://doi.org/10.2105/AJPH.2015.302646

Foundation for Promotion of Cancer Research. (2018) Cancer statistics in Japan-2017 [Internet]. c2018. Retrieved March 1, 2019, from https://ganjoho.jp/en/professional/statistics/brochure/2017_en.html

Hiroshima Prefecture, Japan. Can Do it Because it is Manager [Internet]. c2014. Japanese. Retrieved March 1, 2019, from https://www.pref.hiroshima.lg.jp/uploaded/attachment/124657.pdf

Hori, M., Matsuda, T., Shibata, A., Katanoda, K., Sobue, T., \& Nishimoto, H. (2015). Cancer incidence and incidence rates in Japan in 2009: a study of 32 population-based cancer registries for the Monitoring of Cancer Incidence in Japan (MCIJ) project. Japanese journal of clinical oncology, 45(9), 884-891. https://doi.org/10.1093/jjco/hyv088

Fincham, J. E. (2008). Response rates and responsiveness for surveys, standards, and the Journal. American journal of pharmaceutical education, 72(2). https://doi.org/10.5688/aj720243

Mbengi, R. K., Otter, R., Mortelmans, K., Arbyn, M., Van Oyen, H., Bouland, C., \& De Brouwer, C. (2016). Barriers and opportunities for return-to-work of cancer survivors: time for action-rapid review and expert consultation. Systematic reviews, 5(1), 35. https://doi.org/10.1186/s13643-016-0210-z

Leijten, F. R., de Wind, A., van den Heuvel, S. G., Ybema, J. F., van der Beek, A. J., Robroek, S. J., \& Burdorf, A. (2015). The influence of chronic health problems and work-related factors on loss of paid employment among older workers. $J$ Epidemiol Community Health, 69(11), 1058-1065. https://doi.org/10.1136/jech-2015-205719

Mehnert, A. (2011). Employment and work-related issues in cancer survivors. Critical reviews in oncology/hematology, 77(2), 109-130. https://doi.org/10.1016/j.critrevonc.2010.01.004

Ministry of Economy Trade and Industry. Summary of White Book on Small- and Medium-Sized Companies: Ministry of Economy, Trade and Industry, Japan [Internet]. c2016. Japanese. Retrieved March 1, 2019, from http://www.chusho.meti.go.jp/pamflet/hakusyo/H28/PDF/h28_pdf_mokujityuuGaiyou.pdf

Ministry of Health, Labour and Welfare, Japan. The Guideline for Supporting Work-Treatment Balance in the Workplace [Internet]. c2016. Japanese. Retrieved March 1, 2019, from https://www.mhlw.go.jp/file/04-Houdouhappyou-11201250-Roudoukijunkyoku-Roudoujoukenseisakuka/00 00113625_1.pdf

Paalman, C. H., Van Leeuwen, F. E., Aaronson, N. K., De Boer, A. G. E. M., Van De Poll-franse, L., Oldenburg, H. S. A., \& Schaapveld, M. (2016). Employment and social benefits up to 10 years after breast cancer diagnosis: a population-based study. British journal of cancer, 114(1), 81-87. https://doi.org/10.1038/bjc.2015.431 
Reeuwijk, K. G., Robroek, S. J., Hakkaart, L., \& Burdorf, A. (2014). How work impairments and reduced work ability are associated with health care use in workers with musculoskeletal disorders, cardiovascular disorders or mental disorders. Journal of occupational rehabilitation, 24(4), 631-639. https://doi.org/10.1007/s10926-013-9492-3

Saito, N., Takahashi, M., Sairenchi, T., \& Muto, T. (2014). The impact of breast cancer on employment among Japanese women. Journal of occupational health, 13-0140. https://doi.org/10.1539/joh.13-0140-OA

Sakamoto, H., Matsuoka, K., \& Nishida, T. [Cancer patient employment support-related expectations that offices have of medical institutions: based on an 'Office Survey Regarding Cancer Patient Employment Support' in Chiba Prefecture]. Japanese Journal of Occupational Medicine and Traumatology, 65, 39-46. Japanese.

Sampere, M., Gimeno, D., Serra, C., Plana, M., Martínez, J. M., Delclos, G. L., \& Benavides, F. G. (2011). Organizational return to work support and sick leave duration: a cohort of Spanish workers with a long-term non-work-related sick leave episode. Journal of occupational and environmental medicine, 53(6), 674-679. https://doi.org/10.1097/JOM.0b013e31821f2ad4

Shiga Prefecture, Japan. Survey About Cancer Screening on Workplace [Internet]. c2015. [cited 2019 March 1]. Japanese. $\quad$ Retrieved $\quad$ March $\quad 1, \quad 2019, \quad$ from http://www.kenkou-shiga.or.jp/files/investigate_report_cancer_screening_H2703_summary.pdf

Shimane Prefecture, Japan. Survey About Employment of Cancer Patients [Internet]. c2017. [cited 2019 March 1]. Japanese. Retrieved March 1, 2019, from http://www.pref.shimane.lg.jp/medical/kenko/kenko/gan/shimanetorikumi/H26kyougikai-2.data/shiryou-5-3 .pdf

Nazarov, S., Manuwald, U., Leonardi, M., Silvaggi, F., Foucaud, J., Lamore, K., ... \& Rothe, U. (2019). Chronic diseases and employment: Which interventions support the maintenance of work and return to work among workers with chronic illnesses? A systematic review. International journal of environmental research and public health, 16(10), 1864. https://doi.org/10.3390/ijerph16101864

Tamminga, S. J., De Boer, A. G. E. M., Verbeek, J. H. A. M., \& Frings-Dresen, M. H. W. (2010). Return-to-work interventions integrated into cancer care: a systematic review. Occupational and Environmental Medicine, 67(9), 639-648. https://doi.org/10.1136/oem.2009.050070

Tanaka, H., Toyonaga, T., \& Hashimoto, H. (2011). Functional and occupational characteristics associated with very early return to work after stroke in Japan. Archives of physical medicine and rehabilitation, 92(5), 743-748. https://doi.org/10.1016/j.apmr.2010.12.009

The Japan Institute for Labour Policy and Training (2005) Status Survey on Setting, Change and Personnel Affairs Treatment of Working Conditions [Internet]. c2005. Retrieved March 1, 2019, from https://www.mendeley.com/viewer/?fileId=114e910c-d215-d901-5ec1-0d5bdfdc9570\&documentId=3e2792 c0-0add-3e52-814b-65826508f66f

The Ministry of Health, Labour and Welfare, Japan. The Guidelines for Supporting Work-Treatment Balance at in the Workplace [Internet]. c2016. Retrieved March 1, 2019, from http://www.mhlw.go.jp/file/04-Houdouhappyou-11201250-Roudoukijunkyoku-Roudoujoukenseisakuka/00 00113625_1.pdf

The Small and Medium Enterprise Agency of the Japanese Ministry of Economy Trade and Industry [Internet]. c2014. Japanese. Retrieved March 1, 2019, from http://www.chusho.meti.go.jp/soshiki/teigi.html

White, M., Wagner, S., Schultz, I. Z., Murray, E., Bradley, S. M., Hsu, V., ... \& Schulz, W. (2013). Modifiable workplace risk factors contributing to workplace absence across health conditions: A stakeholder-centered best-evidence synthesis of systematic reviews. Work, 45(4), 1-12. https://doi.org/10.3233/WOR-131628 


\section{Appendix A}

\section{The Heading to Appendix A}

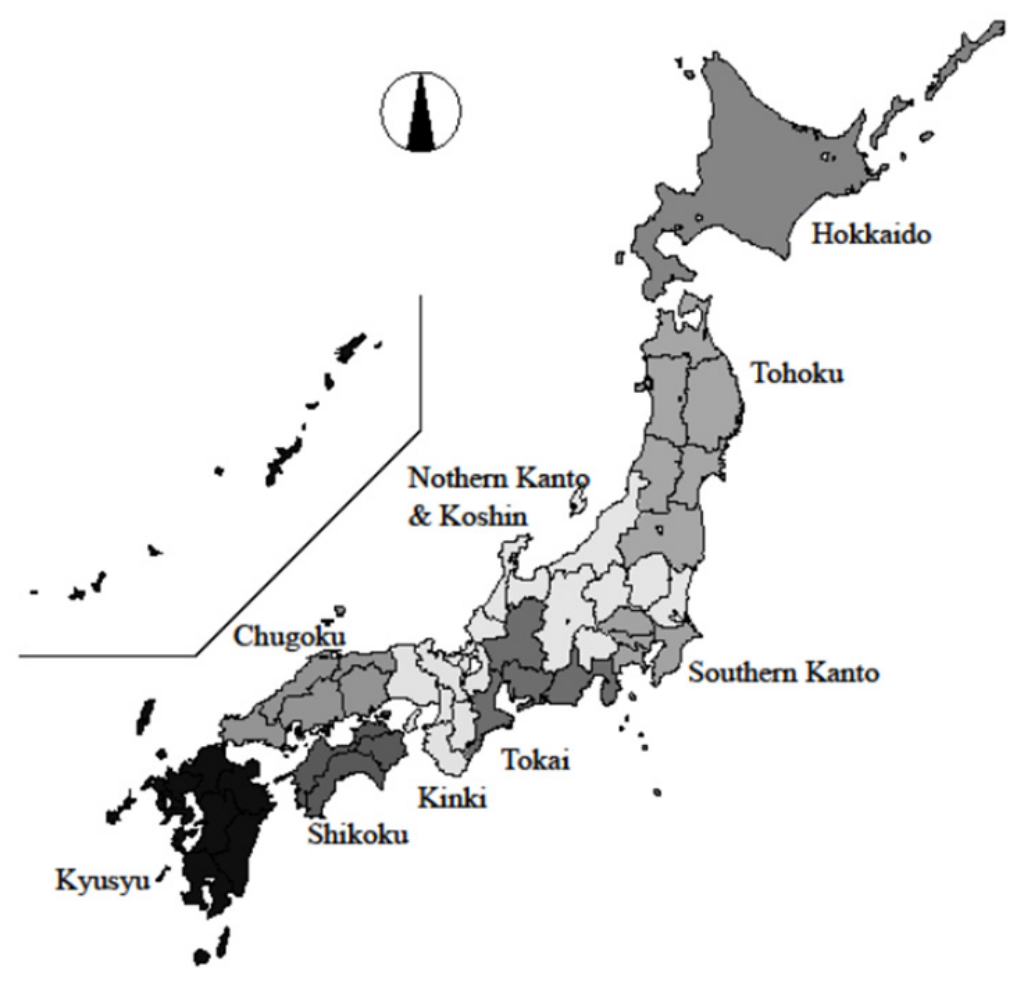

Figure A. The geographic area on a map

\section{Copyrights}

Copyright for this article is retained by the author(s), with first publication rights granted to the journal.

This is an open-access article distributed under the terms and conditions of the Creative Commons Attribution license (http://creativecommons.org/licenses/by/4.0/). 